\title{
Take-off performance of flying fish Cypselurus heterurus doederleini measured with miniature acceleration data loggers
}

\author{
Y. Makiguchi ${ }^{1, *}$, K. Kuramochi ${ }^{1}$, S. Iwane ${ }^{1}$, T. Kojima1 ${ }^{1}$ Y. Naito ${ }^{2}$ \\ ${ }^{1}$ College of Bioresource Science, Nihon University, 1866 Kameino, Fujisawa, Kanagawa 252-0880, Japan \\ ${ }^{2}$ National Institute of Polar Research, 1-9-10 Kaga, Itabashi, Tokyo 173-8515, Japan
}

\begin{abstract}
Flying fish (Teleostei: Exocoetidae) glide at a speed considerably faster than they can travel in water. This phenomenon has been investigated and examined from taxonomic, anatomical, aerodynamic and biological standpoints through field observations. However, direct measurements of the flight performance of flying fish at the moment of leaping from the water surface have not previously been performed, due to the difficulty of monitoring gliding behavior. In the present study, we used recently developed data loggers capable of recording acceleration on a 3dimensional axis to directly examine the gliding behavior of the flying fish Cypselurus heterurus doederleini under controlled conditions. Gliding behavior was assessed with the data logger fixed to the fish in 1 of 2 different positions, and positioning was not found to seriously affect leaping performance, as no effects on pitch angle, amplitude of fluctuation in swaying acceleration, stroke cycle frequency, or the duration of acceleration were observed. Pitch angle $\left(20.0 \pm 3.3^{\circ}\right)$ and stroke cycle frequency $(21.2 \pm 4.6 \mathrm{~Hz})$ were found to be lower in the present study than in previous studies that examined gliding behavior in the field. Additionally, the flying fish were estimated to leap from the water surface at speeds of 3.9 to $5.2 \mathrm{~m} \mathrm{~s}^{-1}$ in our study, which is 38.7 to $51.5 \%$ of previously reported maximum swimming speeds determined using stroboscopic filming. Our results suggest that the flying fish in our study may have recognized the capacity of the experimental space and regulated swimming performance before leaping from the water surface.
\end{abstract}

KEY WORDS: Flying fish · Pitch angle - Acceleration duration - Stroke cycle frequency · Swaying acceleration

\section{INTRODUCTION}

Flying fish (Teleostei: Exocoetidae) are the only marine fish with the unusual ability to glide above the water surface. These fish have a habitat distribution throughout tropical and sub-tropical seas (Rayner 1986), and are a commercially important species in various regions throughout the world (Gomes et al. 1998). Earlier taxonomic and anatomical studies on flying fish have inferred that their high degree of morphological adaptation is coincident with the aerodynamic characteristics of gliders (Breder 1930, Mills 1936, Breder 1937, Fish 1990). Four-winged genera such as Cypsilurus have pelvic fins and a body with a flattened bottom to yield additional lift (Davenport 1992, 1994, Park \& Choi 2010). The gliding performance of flying fish has also been studied using stroboscopic filming (Edgeron \& Breder 1941, Davenport 1990). These studies have reported that flying fish leap from the water surface at a speed of about $10 \mathrm{~m} \mathrm{~s}^{-1}$ and glide for up to $50 \mathrm{~m}$ using their hypertrophied pectoral fins at an air speed of 15 to $20 \mathrm{~m} \mathrm{~s}^{-1}$. The propulsion is generated by the entire caudal fin and posterior body when underwater, and the enlarged lower lobe continues to generate propulsion once its body has left the water. Furthermore, 
some flying fish dip the lower lobe of the caudal fin and beat the tail in a process called taxiing when the gliding speed decreases towards the end of the flight (Rayner 1986, Fish 1990, Davenport 1994). Park \& Choi (2010) examined wing performance of flying fish in detail by means of measuring aerodynamic forces and moment, as well as conducting flow visualizations using a wind tunnel.

As mentioned above, several features of flying fish have been described from the perspectives of morphological function and field observation. However, direct measurements of gliding performance on flying fish have never been conducted because of the technical difficulty of obtaining precise measurements of the high speed and unpredictable flight of flying fish in the field (Davenport 1994). To date, the reasons for flight of flying fish remain unclear. However, it has been suggested that flying fish utilize this behavior to escape from predators, including dolphin fish Coryphaena hippurus, that feed chiefly on the fish (Rayner 1986, Davenport 1994). To identify the flight capability of flying fish, detailed data on gliding performance in the field are required. Hence, the goal of this study was to measure and examine the gliding performance of flying fish Cypselurus heterurus doederleini under controlled field conditions using advanced miniaturized data loggers which can record acceleration on a 3-dimensional axis (sway, surge and heave). We conducted experiments using flying fish in a aquarium where blacktip sharks Carcharhinus melanopterus were kept. We examined whether the burst swimming of the flying fish is associated with escape behavior from the predator, and quantified the escape dynamics.

\section{MATERIALS AND METHODS}

Trials were conducted at Kamogawa Sea World, Chiba Prefecture, Japan, in May 2010 and June 2011. The aquarium in which experiments were conducted was a semicircular column (depth $\times$ length $\times$ width $=$ $7.5 \times 5 \times 10 \mathrm{~m}_{i} 535 \mathrm{~m}^{3}$ ). Ten flying fish Cheilopogon heterurus doederleini (mean \pm SD fork length: $32.5 \pm$ $1.1 \mathrm{~cm}$; mean body mass: $227.4 \pm 18.9 \mathrm{~g}$ ) and 3 flying fish (fork length: $27.2 \pm 2.0 \mathrm{~cm}$; mean body mass 201.3 $\pm 32.4 \mathrm{~g}$ ) were captured by commercial fishers with net in Kamogawa, Chiba Prefecture, Japan, in 2010 and 2011, respectively. The fishes were equipped with cylindrical acceleration data loggers (ORI400D3GT: $12 \mathrm{~mm}$ diameter, $45 \mathrm{~mm}$ length, $9 \mathrm{~g}$ in air; Little Leonardo Co.) capable of recording 3-dimensional axis acceleration (sway, surge and heave, correspon- ding to horizontal, longitudinal and vertical movements, respectively; Fig. 1). The sampling rate of the data loggers was set at $100 \mathrm{~Hz}$. In order to attach the data loggers to the fish, 4 hooks with barbs were fastened around the data loggers using nylon thread and used to fix them on the dorsal surface of the fish, anterior to the dorsal fin and parallel to the body axis, in the first 10 fish (Fig. 1). For the subsequent 3 fish, the loggers were attached as described above to the dorsal surface above the center of mass of the fish, located at the trailing edge of the maximally extended pectoral fin (Davenport 2003; Fig. 1). The attachment procedure required approx. $10 \mathrm{~s}$ to complete, and was performed without anesthesia. It was necessary to attach the data loggers to the flying fish externally because these fish have a flattened ventral body shape to generate extra lift. Therefore, not enough space exists to implant data loggers in the abdominal cavity (Baylor 1967, Davenport 1994). Bridger \& Booth (2003) have also reported that the external attachment procedure has the benefit of being rapid, requiring minimal handling stress and is suitable for short-term research. As no obvious alterations in behavior were observed during the experiments, the attachment method used in the present study appears to be suitable for flying fish. After the data loggers were attached, tagged fish were immediately released to the experimental aquarium, which contained 3 blacktip sharks. The blacktip sharks almost always pursued the tagged flying fish as prey, resulting in the fish

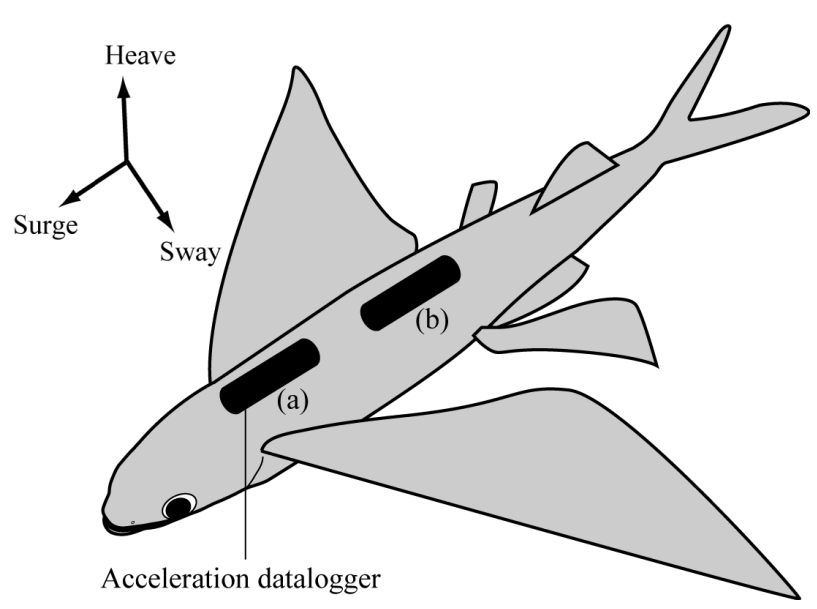

Fig. 1. Attachment locations of the acceleration data loggers on flying fish Cypselurus heterurus doederleini (Teleostei: Exocoetidae) for the measurement of swaying, heaving and surging acceleration. (a) In 2010, the acceleration data logger was fixed on the back of the fish anterior to the dorsal fin. (b) In 2011, the data logger was positioned above the center of body mass of the fish, at approximately $46.0 \%$ of the fish body length from the snout 
swimming rapidly ('burst swimming') and/or leaping from the water surface ('leaping') to escape the predator. When a fish leaped out of the aquarium, the flying fish was caught, the acceleration data logger was retrieved, and the fork length and body mass of the fish were measured. The swimming behavior of the flying fish was monitored visually. The acceleration data loggers measured both dynamic acceleration (tail stroke frequency) and static acceleration along the body axis (gravity or pitch). Surging acceleration, which measured the component of gravitational acceleration accompanying the pitch angle of the fish when not moving or moving at a constant rate, was calculated along the longitudinal body axis of the fish (Tanaka et al. 2001, Yoda et al. 2001, Watanabe et al. 2006). To separate these values, a continuous wavelet transform (CWT) filter with Igor Pro (WaveMetrics) and Ethographer software (Sakamoto et al. 2009) was used to extract the information on tail beat stroke frequency from swaying acceleration and pitch from surging acceleration, respectively. Pitch angle was determined at the moment of the maximum leaping angle from extracted surging acceleration to synchronize the visual observation records. Acceleration duration was defined as the time from when the fish began to glide or show burst swimming underwater to when the fish emerged from the water surface in order to escape from the shark. Amplitude of fluctuation in surging acceleration was calculated from fluctuation in the pitch angle. Values recorded by the acceleration data loggers were converted into acceleration $\left(\mathrm{m} \mathrm{s}^{-2}\right)$ using Igor Pro software.

Pitch angle, amplitude of fluctuation in swaying acceleration, stroke cycle frequency acceleration duration and amplitude of fluctuation in surging acceleration were calculated by using linear mixed models to examine the effects of the position of the data loggers, as well as the behavior of the fish (gliding or burst swimming). Linear mixed models were also used to determine whether the behavior of the fish (gliding or burst swimming) or fish size, such as fork length or body mass, influenced the correlations between acceleration duration and stroke cycle frequency. Fish identity used in a trial was treated as a random effect in the models to avoid a pseudoreplication. The calculated models were fitted with the function lmer from the package lme4 in the software R 2.11 (R Development Core Team 2010), and $95 \%$ confidence intervals and p-values of each parameter were estimated by comparisons to a probability distribution obtained by 10000 Markov chain Monte Carlo simulations with the function pvals.fnc from package language R (Baayen et al. 2008).

\section{RESULTS}

The acceleration data for 7 leaping and 18 burst swimming behaviors in 2010 and 3 gliding and 8 burst swimming behaviors in 2011 were recorded for 13 tagged flying fish (Table 1). Six of the 10 flying fish in 2010 and the 3 flying fish in 2011 that were pursued by the blacktip sharks flew out of the aquarium and landed on the ground. It was possible to retrieve all acceleration data loggers used in the experiment. The flying fish also showed burst swimming to escape from the blacktip reef shark under water without successful gliding. In order to compare the effects of the position of the data loggers on the gliding behavior of the fish, we compared pitch angle, amplitude of fluctuation in swaying acceleration, stroke cycle frequency and acceleration duration between the 2010 and 2011 experiments (Table 2). No significant differences were observed, indicating that the position of data logger attachment did not affect gliding behavior of the fish. We thus pooled data for the pitch angle, amplitude of fluctuation in swaying acceleration, stroke cycle frequency, acceleration duration and amplitude of fluctuation in surging acceleration and compared those values between when flying fish were either successfully taking off or swimming fast to escape from the sharks. The amplitude of fluctuation in swaying acceleration and stroke frequency seemed to be similar between the underwater

Table 1. Cypselurus heterurus doederleini. Summary of the physical characteristics and behavior of tagged flying fish. $\mathrm{n}$ : number of fish

\begin{tabular}{|lccccc|}
\hline $\begin{array}{l}\text { Fish } \\
\text { ID }\end{array}$ & Year & $\begin{array}{c}\text { Fork } \\
\text { length } \\
(\mathrm{mm})\end{array}$ & $\begin{array}{c}\text { Body } \\
\text { mass } \\
(\mathrm{g})\end{array}$ & $\begin{array}{c}\text { Leaping } \\
(\mathrm{n})\end{array}$ & $\begin{array}{c}\text { Burst } \\
\text { swimming } \\
(\mathrm{n})\end{array}$ \\
\hline A & 2010 & 322 & 247 & 0 & 0 \\
$\mathrm{~B}$ & 2010 & 325 & 231 & 1 & 0 \\
$\mathrm{C}$ & 2010 & 325 & 214 & 1 & 3 \\
$\mathrm{D}$ & 2010 & 334 & 263 & 1 & 2 \\
E & 2010 & 315 & 202 & 0 & 2 \\
$\mathrm{~F}$ & 2010 & 300 & 198 & 1 & 3 \\
G & 2010 & 330 & 223 & 0 & 0 \\
$\mathrm{H}$ & 2010 & 335 & 238 & 0 & 2 \\
I & 2010 & 324 & 227 & 0 & 0 \\
J & 2010 & 340 & 234 & 2 & 2 \\
K & 2011 & 295 & 238 & 1 & 5 \\
L & 2011 & 257 & 188 & 1 & 2 \\
M & 2011 & 265 & 178 & 2 & 2 \\
Average & $325.0 \pm 11.4$ & $227.7 \pm 19.8$ & & \\
Total & & & & 10 & 23 \\
\hline
\end{tabular}


Table 2. Cypselurus heterurus doederleini. Pitch angle, amplitude of fluctuation in swaying acceleration, stroke cycle frequency, duration of acceleration just before leaping and amplitude of fluctuation in surging acceleration (mean \pm SE) according to position of attached data loggers: anterior to dorsal fin (2010), and over the center of mass (2011). None of the values were significantly different at $\mathrm{p}<0.05$

\begin{tabular}{|lcccccc|}
\hline $\begin{array}{l}\text { Position of attached } \\
\text { data loggers }\end{array}$ & $\mathrm{n}$ & $\begin{array}{c}\text { Pitch angle } \\
\left({ }^{\circ}\right)\end{array}$ & $\begin{array}{c}\text { Amp. swaying } \\
\text { acceleration }\left(\mathrm{m} \mathrm{s}^{-2}\right)\end{array}$ & $\begin{array}{c}\text { Stroke cycle } \\
\text { frequency (Hz) }\end{array}$ & $\begin{array}{c}\text { Acceleration } \\
\text { duration }(\mathrm{s})\end{array}$ & $\begin{array}{c}\text { Amp. surging } \\
\text { acceleration }\left(\mathrm{m} \mathrm{s} \mathrm{s}^{-2}\right)\end{array}$ \\
\hline $\begin{array}{l}\text { Anterior to dorsal fin } \\
\text { Center of mass }\end{array}$ & 6 & $19.6 \pm 4.1$ & $8.78 \pm 0.21$ & $21.3 \pm 5.1$ & $0.47 \pm 0.13$ & $3.40 \pm 0.38$ \\
p-value & 4 & $\begin{array}{c}18.6 \pm 4.0 \\
0.49\end{array}$ & $\begin{array}{c}8.83 \pm 0.14 \\
0.62\end{array}$ & $\begin{array}{c}20.0 \pm 3.9 \\
0.57\end{array}$ & $\begin{array}{c}0.51 \pm 0.07 \\
0.58\end{array}$ & 0.43 \\
\hline
\end{tabular}
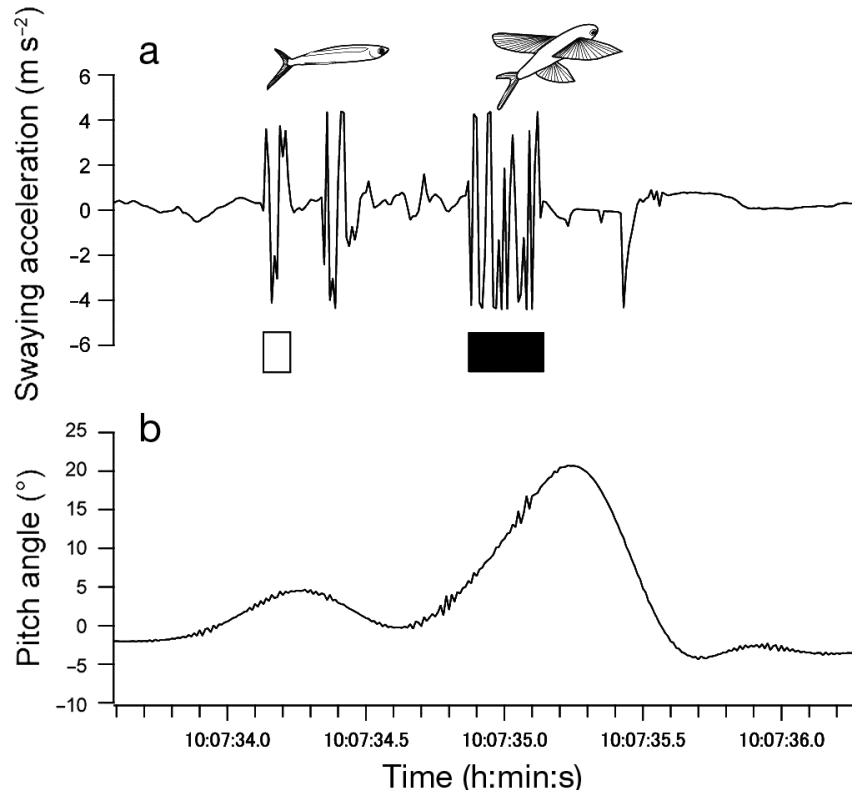

Fig. 2. Cypselurus heterurus doederleini. Typical profiles for (a) swaying acceleration and (b) pitch angle of a flying fish; representative results are shown for Fish E (Table 1). Bars represent duration of burst swimming behavior (open) and duration of gliding behavior (closed) at the moment of leaping from the surface of the water. During the waterborne phase, the fish undergoes significant sway (a) as the pitch angle increases (b). Once airborne, the fish undergoes significant sway as the pitch angle increases swimming and the gliding, although not quantified, but as the fish became airborne the pitch angle changed up to approximately $20^{\circ}$ (Fig. 2). The flying fish were found to have oscillated their tails for (mean $\pm \mathrm{SE}$ ) $0.46 \pm 0.10 \mathrm{~s}$, with a $21.2 \pm 4.6 \mathrm{~Hz}$ stroke cycle frequency $(n=10)$, just before leaping through the water surface at $20.0 \pm 3.3^{\circ}(\mathrm{n}=10$; Table 3), with the angle of incidence to the horizon. Amplitude of fluctuation in swaying acceleration and stroke cycle frequency values did not differ between when the flying fish were taking off and swimming to escape from the predator under water (Table 3). However, the pitch angle calculated from surging acceleration, acceleration duration and amplitude of fluctuation in surging acceleration was significantly higher when the flying fish were leaping than when they were swimming under water.

Correlations between stroke cycle frequency and acceleration duration during burst swimming were significantly different between burst swimming and gliding ( $\mathrm{p}<0.0001$; Table 4). Fork length and body mass of fish were not found to significantly affect the correlations between stroke cycle frequency and acceleration duration, respectively (Table 4). While significant correlation between stroke cycle frequency and acceleration duration was detected in both burst swimming and gliding, there was

Table 3. Cypselurus heterurus doederleini. Pitch angle, amplitude (amp.) of fluctuation in swaying acceleration, stroke cycle frequency, duration of acceleration and amplitude of fluctuation in surging acceleration (mean \pm SE) during leaping and burst swimming behavior of flying fish. Significant differences (at $p<0.05$ ) between leaping and burst swimming behavior are indicated with an asterisk

\begin{tabular}{|lcccccc|}
\hline Behavior & $\mathrm{n}$ & $\begin{array}{c}\text { Pitch angle } \\
\left(^{\circ}\right.\end{array}$ & $\begin{array}{c}\text { Amp. swaying } \\
\text { acceleration }\left(\mathrm{m} \mathrm{s}^{-2}\right)\end{array}$ & $\begin{array}{c}\text { Stroke cycle } \\
\text { frequency (Hz) }\end{array}$ & $\begin{array}{c}\text { Acceleration } \\
\text { duration }(\mathrm{s})\end{array}$ & $\begin{array}{c}\text { Amp. surging } \\
\text { acceleration }\left(\mathrm{m} \mathrm{s} \mathrm{s}^{-2}\right)\end{array}$ \\
\hline Leaping & 10 & $20.0 \pm 3.3$ & $8.80 \pm 0.18$ & $21.2 \pm 4.6$ & $0.46 \pm 0.10$ & $3.30 \pm 0.48$ \\
Burst swimming & 25 & $\begin{array}{c}9.49 \pm 3.9 \\
<0.01^{*}\end{array}$ & $\begin{array}{c}8.74 \pm 0.28 \\
0.37\end{array}$ & $\begin{array}{c}22.3 \pm 4.7 \\
0.55\end{array}$ & $\begin{array}{c}0.22 \pm 0.11 \\
<0.01^{*}\end{array}$ & $\begin{array}{c}1.68 \pm 0.46 \\
<0.01^{*}\end{array}$ \\
\hline
\end{tabular}


Table 4. Cypselurus heterurus doederleini. Linear mixed model to test the effects of variables on correlations between accelerating duration and frequency. Behavior: leaping or burst swimming; AIC: Akaike's information criteria; CI: $95 \%$ confidence interval

\begin{tabular}{|lccccc|}
\hline \multirow{2}{*}{ Variables } & \multirow{2}{*}{$\begin{array}{c}\text { Stroke cycle freq. } \\
\text { AIC }\end{array}$} & \multicolumn{2}{c}{ Stroke cycle freq. + variables } & $\mathrm{p}$ \\
& AIC & Lower CI & Upper CI & \\
\hline Behavior & -15.04 & -31.00 & 0.1270 & 0.2980 & $<0.0001$ \\
Fork length & -15.04 & -13.44 & -0.0004 & 0.0007 & 0.57 \\
Body mass & -15.04 & -13.38 & -0.0023 & 0.0035 & 0.60 \\
\hline
\end{tabular}

\section{DISCUSSION}

In the present study, we conducted a direct measurement of the flight performance of flying fish using 3dimensional acceleration data loggers. There were no significant differences in amplitude of fluctuation in swaying acceleration values between when the flying fish were leaping and when they were showing burst swimming behavior to escape from the predator under water. However, the

more significant negative correlation between stroke cycle frequency and acceleration duration in gliding ( $\mathrm{n}=10, \mathrm{p}<0.001$ ) than during burst swimming $(\mathrm{n}=25, \mathrm{p}<0.05)$, which were estimated as acceleration duration $=-0.021$ stroke cycle frequency +0.919 in gliding and acceleration duration $=-0.009$ stroke cycle frequency +0.430 in burst swimming (Fig. 3).

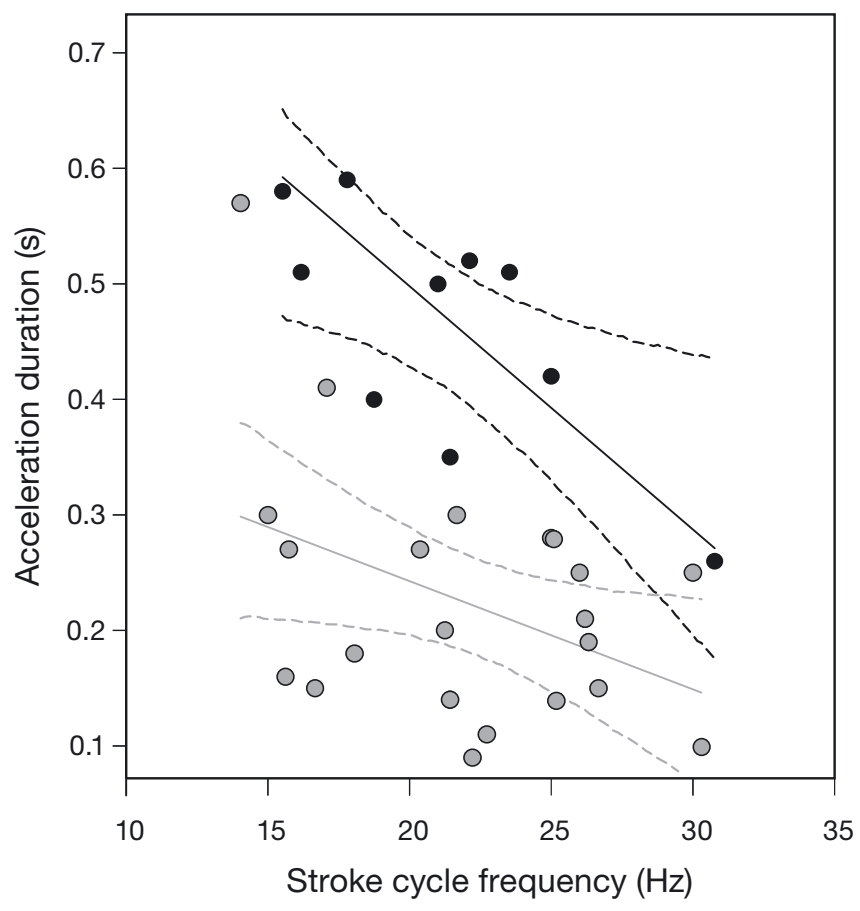

Fig. 3. Cypselurus heterurus doederleini. Correlation between stroke cycle frequency and acceleration duration in leaping $(\bigcirc)$ and burst swimming $(\bigcirc)$ fish. Based on the acceleration data, stroke cycle frequency and acceleration duration were significantly correlated with leaping behavior $(\mathrm{n}=9$; $\mathrm{p}<0.001$ ), but not with burst swimming behavior $(\mathrm{n}=11$; $\mathrm{p}=0.312$ ). Solid lines represent fitted linear regressions for leaping behavior, described as follows: acceleration duration $=-0.017$ stroke cycle frequency +0.832 . Dashed lines represent $95 \%$ confidence intervals pitch angle of the flying fish in the present study was significantly higher just before leaping out of the water $\left(20.0 \pm 3.3^{\circ}\right)$ than it was during burst swimming under water $\left(9.5 \pm 3.9^{\circ}\right)$. Previous studies have shown that flying fish leap from the sea surface at a $30^{\circ}$ pitch angle relative to the horizon, with velocities of approximately 20 to 30 body lengths $\mathrm{s}^{-1}$, as determined by indirect methods using stroboscopic filming and subsequent aerodynamic analysis (Edgerton \& Breder 1941, Davenport 1994). In contrast, Park \& Choi (2010) performed direct wind-tunnel experiments to examine the aerodynamic properties of flying fish, and found that the lift coefficient of flying fish when emerging from the sea peaked at a pitch angle of around 30 to $35^{\circ}$. Therefore, the pitch angle recorded in this study is lower than those previously reported; this probably had to do with the stability of gliding. Horizontal distance travelled by the flying fish without lift generation from the fins and taxiing flight can be expected to follow a projectile path according to the equation: $D=\left(V^{2} \sin 2 H\right) / g$, where $D$ is the horizontal distance travelled, $V$ is initial velocity, $H$ is the take off angle relative to the horizon and $g$ is gravitational acceleration. In this situation, a pitch angle of $45^{\circ}$ maximizes the horizontal distance travelled. Thus, the horizontal distance travelled by the flying fish as expected from the take-off pitch angle measured in the present study would be shorter than those previously reported (Davenport 1994). To investigate the gliding behavior in greater detail, we predicted the maximum swimming speed $\left(U_{\max }\right)$ of a submerged fish using the formula described by Wardle (Wardle 1975): $U_{\max }=Y L / 2 T$, where $Y$ is stride length defined as the forward motion in 1 tail beat cycle, expressed as a proportion of body length, $L$ is fish length and $T$ is 1 contraction time of the swimming muscles ( 2 contraction times is equivalent to 1 tail beat cycle). Thus, maximum swimming speed is dependent upon $Y$ and $T$ for fish of similar body lengths, even for different species. 
Wardle (1975) found that the physiological and mechanical muscle properties of fish restrict maximum tail beat frequency. The muscle properties are similar in different fish with the same body length under similar water temperature conditions and a stride length of between 0.6 and 0.8 times $L$. In the present study, 9 flying fish $(30.8 \pm 3.1 \mathrm{~cm})$ exhibited a stroke cycle frequency of $21.2 \pm 4.6 \mathrm{~Hz}$ at the point of leaving the water surface. If the flying fish had used their predicted stride length of 0.6 to 0.8 times $L$, maximum swimming speed would have been predicted to reach 3.87 to $5.15 \mathrm{~m} \mathrm{~s}^{-1}$ when jumping from the water surface. Using stroboscopic filming methods, Davenport (1994) found that flying fish approached and leaped from the water surface at approximately $10 \mathrm{~m} \mathrm{~s}^{-1}$ (20 to 30 body length $\mathrm{s}^{-1}$ ), a speed shown to be the maximum cavitations-free velocity (Iosilevskii \& Weihs 2008). Furthermore, measured tail beat frequency (stroke cycle frequency) and predicted maximum swimming speeds of the flying fish in the present study were lower than those of previous studies. It is likely that the flying fish used in the present study leaped from the water surface using weaker force than those observed in the field (Edgerton \& Breder 1941, Rayner 1986, Davenport 1994), which may be a result of the size limitation of the aquarium.

Two factors may have affected the take-off pitch angle and stroke cycle frequency of flying fish observed in the present study. Firstly, the gliding and swimming behavior of flying fish may have been hampered by the attached data loggers. The loggers represented 3.42 to $5.06 \%(4.11 \pm 0.48 \%)$ of the fish's body mass. Ultrasound transmitters or data loggers should weigh no more than $2 \%$ of a fish's body mass in air to exclude adverse effects according to Winter (1983). However, the fact that stroke cycle frequency did not differ between burst swimming and gliding does not preclude the possibility that the data loggers affected both behaviors.

Secondly, drag effects due to the cross-sectional area of the data logger in the water, swimming performance with tagged fish requiring greater tail beat frequency (proportional to the square of water velocity, Bridger \& Booth 2003). Lewis \& Muntz (1984) found that fish with attached transmitters showed greater fin amplitudes to compensate for the effects of the load. However, in the present study, stroke cycle frequency did not significantly differ between gliding $(20.9 \pm 1.7 \mathrm{~Hz})$ and burst swimming behavior $(22.1 \pm 1.1 \mathrm{~Hz})$. Davenport (1994) reported that flying fish approached the water surface at approximately $10 \mathrm{~m} \mathrm{~s}^{-1}$, which could lead to a possible tail beat fre- quency of 41.7 to $55.6 \mathrm{~Hz}$, as predicted using the formula for $U_{\max }$. These results indicate that drag produced by the attached data loggers did not affect swimming performance, including gliding behavior when the fish leaped from the water surface. Further, there were no significant differences in pitch angle, stroke cycle frequency, or acceleration duration at the moment of gliding behavior when the attachment position of the data loggers was changed from an anterior position in 2010 to directly above the center of mass of the fish in 2011. Davenport (2003) demonstrated that the positioning of the center of body mass behind the pectoral fins is important for stability in gliding, which would contribute to an increased pitch angle. We speculate that the fish were not performing maximally because the aquarium was smaller than needed to attain maximal take-off speed and distance. Consequently, they were not pushing their performance variables to the extreme, and, as a result, the pitch angle did not differ between the 2 positions of data logger attachment. These results also suggest that the attachment of a data logger did not significantly influence the gliding behavior of the fish in this study under these sub-optimal conditions.

We also consider the possibility that flying fish might recognize ambient environments, such as the space of the aquarium in which experiments were conducted or the presence of a predator, resulting in sub-maximal performance before they leaped from the water surface. Flying fish have large eyes with flattened pyramidal cornea that permit focusing in both water and air (Baylor 1967, Davenport 1994). It has also been noted by Davenport (1994) that flying fish presumably identify the wind direction using visual cues provided by the underside disturbance of the water surface. The results of the present study indicate that flying fish may have obtained information on the size of the swimming aquarium (depth $x$ length $\times$ width $=7.5 \times 5.0 \times 10.0 \mathrm{~m}$ ) or the slow consistent manner of the predator (Economakis \& Lobel 1998), and adjusted their swimming performance before leaping from the water surface or performed sub-maximal leaps to avoid these sharks due to the aquarium size.

We also found that there were significant negative correlations between acceleration duration and stroke cycle frequency during gliding behavior (Fig. 3). However, this relationship was not affected by the fork length or body mass of the fish, indicating that a certain level of force may be required for flying fish to be able to leap from the water surface. Webb (1986) reported that prey do not always escape from predators with the highest speed and acceleration possible. 
Furthermore, Domenici \& Blake (1997) noted that motivation is one of the important factors determining the fast start performance of fish escaping from a predator. The key factor determining the relationship between acceleration duration and stroke cycle frequency during gliding behavior remains unclear, and future studies are needed. However, the significant negative correlation between stroke cycle frequency and acceleration duration in leaping observed in this study may provide evidence that flying fish deliberately regulate swimming performance, including swimming speed and pitch angle, according to their ambient environment before leaping from the water surface. Davenport (1994) pointed out that flights of flying fish would have to be set against energy-saving strategies, because burst swimming of teleost fish at extremely high speeds are achieved by constriction of white axial muscles (Jayne \& Lauder 1994). Our results indicated, however, that regulation of swimming performance according to ambient environment may contribute to energy conservation when leaping from the water surface.

Acknowledgements. We thank the staff of Kamogawa Sea World, Kamogawa, Japan, for capturing the experimental fish, and for their assistance with experiments. We also thank A. Takahashi, Natural Institute of Polar Research, for the loan of the acceleration data loggers.

\section{LITERATURE CITED}

Bayen RH, Davidson DJ, Bates DM (2008) Mixed-effects modeling with crossed random effects for subjects and items. J Mem Lang 59:390-412

Baylor ER (1967) Air and water vision of the Atlantic flying fish, Cypselurus heterurus. Nature 214:307-309

> Breder CM (1930) On the structural specialization of flying fishes from the standpoint of aerodynamics. Copeia 4: 114-121

> Breder CM (1937) The perennial flying fish controversy. Science 86:420-422

> Bridger CJ, Booth RK (2003) The effects of biotelemetry transmitter presence and attachment procedures on fish physiology and behavior. Rev Fish Sci 11:13-34

Davenport J (1990) Observations on the locomotion of postlarval and juvenile flying fish. J Mar Biol Assoc UK 70: 311-320

> Davenport J (1992) Wing-loading, stability and morphometric relationships in flying fish (Exocoetidae) from the north-eastern Atlantic. J Mar Biol Assoc UK 72:25-39

Davenport J (1994) How and why do flying fish fly? Rev Fish Biol Fish 4:184-214

Editorial responsibility: Christine Paetzold, Oldendorf/Luhe, Germany
Davenport J (2003) Allometric constraints on stability and maximum size in flying fishes: implications for their evolution. J Fish Biol 62:455-463

> Domenici P, Blake RW (1997) The kinematics and performance of fish fast-start swimming. J Exp Biol 200: 1165-1178

> Economakis EA, Lobel PS (1998) Aggregation behavior of the grey reef shark, Carcharhinus amblyrhynchos, at Johnston Atoll, Central Pacific Ocean. Environ Biol Fishes 51:129-139

Edgerton HE, Breder CM (1941) High speed photographs of flying fishes in flight. Zoologica 26:311-313

Fish FE (1990) Wing design and scaling of flying fish with regard to flight performance. J Zool (Lond) 221:391-403

> Gomes C, Dales RBG, Oxenford HA (1998) The application of RAPD markers in stock discrimination of the four-wing flying fish, Hirundichthys affinis in the central western Atlantic. Mol Ecol 7:1029-1039

Iosilevskii G, Weihs D (2008) Speed limits on swimming of fishes and cetaceans. J R Soc Interface 5:329-338

Jayne BC, Lauder GV (1994) How swimming fish use slow and fast muscle fibers - implications for models of vertebrate muscle recruitment. J Comp Physiol A 175:123-131

Lewis AE, Muntz WRA (1984) The effects of external ultrasonic tagging on the swimming performance of rainbowtrout, Salmo gairdneri richardson. J Fish Biol 25:577-585

Mills CA (1936) Source of propulsive power used by flying fish. Science 83:80

Park H, Choi H (2010) Aerodynamic characteristics of flying fish in gliding flight. J Exp Biol 213:3269-3279

Rayner JMV (1986) Pleuston: animals which move in water and air. Endeavour 10:58-64

R Development Core Team (2010) A language and environment for statistical computing. R Fundation for Statistical Computing, Vienna

Sakamoto KQ, Sato K, Ishizuka M, Watanuki Y, Takahashi A, Daunt F, Wanless S (2009) Can ethograms be automatically generated using body acceleration data from freeranging birds? PLoS ONE 4:e5379

> Tanaka H, Takagi Y, Naito Y (2001) Swimming speeds and buoyancy compensation of migrating adult chum salmon Oncorhynchus keta revealed by speed/depth/acceleration data logger. J Exp Biol 204:3895-3904

Wardle CS (1975) Limit of fish swimming speed. Nature 255: 725-727

Watanabe Y, Baranov EA, Sato K, Naito Y, Miyazaki N (2006) Body density affects stroke patterns in Baikal seals. J Exp Biol 209:3269-3280

Webb PW (1986) Effect of body form and response threshold on the vulnerability of four species of teleost prey attacked by largemouth bass (Micropterus salmoides). Can J Fish Aquat Sci 43:763-771

Winter JD (1983) Underwater biotelemetry. In: Nielsen LA, Johnson DL (eds) Fisheries techniques. American Fisheries Society, Bethesda, MD, p 371-395

- Yoda K, Naito Y, Sato K, Takahashi A and others (2001) A new technique for monitoring the behaviour of freeranging Adelie penguins. J Exp Biol 204:685-690

Submitted: May 14, 2012; Accepted: January 21, 2013

Proofs received from author(s): February 26, 2013 